\title{
Knowledge Management in R\&D Teams at a Spanish Technical University: Measurement and Relations with Organizational Culture
}

\author{
${ }^{1}$ Universidad Europea de Valencia \\ General Elio, 8, E-46010 Valencia, Spain \\ E-mail.vicentejavier.prado@uem.es \\ ${ }^{2}$ University of Valencia \\ Avda Blasco Ibanez 21, E-46010 Valencia, Spain \\ E-mail. ismael.quintanilla@uv.es \\ ${ }^{3}$ University of Valencia \\ C / Gasco Oliag 3, E-46010 Valencia, Spain \\ E-mail.ferran.calabuig@uv.es \\ ${ }^{4}$ Lithuanian Sports University \\ Sporto str. 6, LT-44221 Kaunas, Lithuania \\ E-mail. jolita.vveinhardt@gmail.com
}

Vicente J. Prado-Gasco ${ }^{1}$, Ismael Quintanilla Pardo ${ }^{2}$, Ferran Calabuig-Moreno ${ }^{3}$, Jolita Vveinhardt ${ }^{4}$

cross $^{\text {ref }}$ http://dx.doi.org/10.5755/j01.ee.26.4.9885

\begin{abstract}
The aim of this study was to create and analyze the psychometric properties of an instrument (Knowledge Creation and Dissemination Survey, KCD) to evaluate the knowledge management on Spanish R\&D teams based on the Leonard-Barton's (1995) model of knowledge flows. For this purpose, three different tasks were carried out: firstly analyzing the psychometric properties of the instrument; secondly, analyzing the knowledge management levels of the R\&D teams at a technical university as well as the relationship between organizational culture and knowledge management. This instrument was developed to cover the existing gap in the evaluation of knowledge management. The "Knowledge Creation and Dissemination Survey" was administered to four different samples from a Spanish technical university. Here we will refer to the sample used for the final validation of the scale, 275 participants from $35 R \& D$ teams. The psychometric properties of the "Knowledge Creation and Dissemination Survey" are adequate. According to the results of the study, the use of this diagnostic tool with university $R \& D$ teams seems justified, the knowledge management on these teams seems to be high considering the levels on the KCD dimensions, and there is a link between organizational culture and knowledge management. The main limitation of the study refers to the sample, future research must continue, extending the sample both in terms of its size and also on its diversity. The paper contributes to management research by presenting a useful, practical tool to evaluate group practices on knowledge management, and by present empirical evidence of the links between organizational culture and knowledge management.
\end{abstract}

Keywords: Knowledge Management; KCD, Knowledge Creation Diffusion; Organizational Culture; Validation.

\section{Introduction}

Relevance of the research. Our society, as several authors have suggested, is a knowledge-based society, in which knowledge is the key factor of the economic systems (Quinn, 1992; Drucker, 1993; Leonard-Barton, 1995; Nonaka \& Takeuchi, 1995; Chang et al., 2004; etc.). Consequently, knowledge and its creation, capture, storage, dissemination and use will be increasingly needed in the society towards which we are moving (Bell, 1973; Drucker, 1993), coming the knowledge management (KM) to be the most appropriate strategy to streamline the flow of knowledge in organizations.

The efficient KM has become a competitive advantage (King \& Zeithaml, 2001; Zhuge, 2002; Halawi et al., 2008; Massa \& Testa, 2009; Heng \& Chua, 2010; etc.). In this line, several authors agree that knowledge and its efficient management appear to improve organizational performance and thus the competitiveness of organizations (LeonardBarton, 1995; Grant, 1996; Prusak, 1996; Sedziuviene \& Vveinhardt, 2009, 2010; Chang \& Chuang, 2011; Melnikas, 2011; Ramirez, \& Morales, 2011; Ramirez \& Girdauskiene, 2013a, 2013b; Rodriguez, 2013, 2014; Alves, 2014; Birasnav, 2014; Martin-Rojas et al., 2014; Thoene \& Buszko, 2014; Zieba \& Zieba, 2014). In general, the benefits of KM seem to have an impact on greater productivity and efficiency, reduction of costs and increase in revenues.

All this is achieved by providing faster and more efficient ways of solving problems, reducing some of the errors or defects in products or processes themselves, or by providing more efficient ways to achieve a certain goal. Along with these benefits, the KM also appears to have other benefits that can sometimes be more difficult to quantify, such as increasing innovation, improving 
customer service, increasing the speed with which products or services are introduced in the market, increasing staff motivation and involvement, promoting the ability of organizations to anticipate problems, reducing drop-out rates and staff rotation, improving the adaptation of an organization or group to its environment, facilitating the learning capacity of employees, or improving teamwork and quality on organization, to name just a few examples (Nonaka \& Takeuchi, 1995; Carnerio, 2000; Gibbert et al., 2002; Zeithaml \& King, 2003; Choi \& Lee, 2003; Yang \& Wan, 2004; Massa \& Testa, 2009; Mohamed et al., 2009; Heng \& Chua, 2010; Cantnera et al., 2011; An et al., 2014; Srisamran \& Ractham, 2014; etc.).

Object of the research: measuring knowledge management in R\&D teams.

The aim of this research was to create and analyze the psychometric properties of an instrument (Knowledge Creation and Dissemination Survey, KCD) to evaluate the knowledge management on Spanish R\&D teams based on the Leonard-Barton's (1995) model of knowledge flows.

To achieve this aim three different tasks were carried out, firstly analyzing the psychometric properties of $\mathrm{KCD}$, secondly analyzing the KM on university $\mathrm{R} \& \mathrm{D}$ teams and finally testing the relationship between organizational culture and $\mathrm{KM}$

Problem of the research. However, despite its importance, there is no single definition or frame of reference for studying knowledge and its management. Summarizing the ideas appearing in the different definitions over the years, we could establish that the KM is a structured and systematic process, which consists of different phases (capture, creation, organization, storage, distribution and effective use of knowledge) in relation to knowledge (not information), which do not necessarily follow a chronological linearity. In this process three key components must be considered - people, knowledge and technologies -, trying to find the best fit between person-knowledge (not any knowledge to any person) using technology (ICT) as a means to a more effective management of the procedure, acting differentially in the different phases of which it consists. Also it represents a key element of business strategy and management, providing a way to gain competitive advantage and to maintain them over time.

\section{Theoretical Background}

The efficient KM in an organization depends on many factors, from which the Organizational Culture (OC) can be highlighted. In this sense, a considerable amount of empirical and theoretical research argues that the OC prevailing in an organization may, among other features, constitute one of the barriers or one the most important facilitators in the KM, both for its implementation and operation (McManus \& Loughridge, 2002; Thoben et al., 2002; Mason \& Pauleen, 2003; Hong et al., 2011; etc.). The OC can both promote or prevent the creation of knowledge as well as its sharing and use, determining which values, beliefs and systems of work are appropriate in an organization (Leonard-Barton, 1995; Gold et al., 2001; Prasarnphanich \& Janz, 2003; etc.). No KM program will succeed without paying attention to the OC of the organizations where it is intended to be implemented (Yang \& Wan, 2004).

In this sense, the cultures showing improved KM are those that relate to collaborative environments, with a focus on teamwork, with more face to face interactions (Hult, 1998; Hult et al., 2000; Prasarnphanich \& Janz, 2003), more on constructive cultures than on defensive (Cooke \& Lafferty, 1987), cultures where commitment comes first (Denison \& Neale, 2000), because such cultures encourage confidence and support environments, which promote social interaction and enable access to information and resources, but also, and perhaps most importantly, an efficient dissemination and use of knowledge (Chen \& Huang, 2007).

As already stated, there is an extensive amount of information, especially in its theoretical dimension, on the importance and implications of the KM to improve the organizational performance and thus the competitiveness of organizations (Barney, 1991; Leonard-Barton, 1995; Grant, 1996; Berman et al., 2002; Choi \& Lee, 2003; Chua \& Heng, 2010; Chang \& Chuang, 2011; etc.). However, much of the existing literature has been based more on theoretical and not on empirical approaches (Chen \& Chen, 2006).

In this regard, according to what (Chen \& Chen, 2006) suggests, interest on measurement in $\mathrm{KM}$ is a recent challenge, since traditionally most of the literature in the area seems to have focused on the theory, the creation of models and the proposal of intervention programs. In this emerging discipline, studies based on qualitative techniques have proliferated (Fenwick, 2005; Lettieri et al., 2004, Yang \& Wan, 2004) or case studies, whether based on large companies such as BP, Xerox, AMP, Ernst \& Young or specific sectors (Pan \& Scarbrough, 1998; Bowen, 1999; Massa \& Testa, 2009; Heng \& Chua, 2010; etc.).

Nevertheless, both qualitative measures and case studies show, from our point of view, serious limitations that prevent generalization of the results (Sanchez et al., 1999), particularly in relation to the statistic treatment that can be done. Furthermore, the results are usually based on the perceptions of business managers, ignoring the importance of the perception of the workforce. For all these reasons to that extent, we believe that the best way to approach the study of basic skills that promote efficient KM is through quantitative measures that allow the use of sophisticated statistical methods. We therefore will argue for the use of questionnaires.

In the review we have done it has been found that this type of practice is not usually very common; in those cases where some kind of self-report instrument has been used, generally more reference was made to some particular knowledge, especially in the medical field (Ponte \& JohnsonTribino, 2005; Steyn et al., 2005; etc.) than to generic concepts of KM. Those studies, which have focused on the $\mathrm{KM}$, usually instead of considering it holistically, they have focused on a particular aspect (Singh et al., 2006) such as absorptive capacity (Harrington \& Guimaraes, 2005; Camison \& Fores, 2010; etc.), satisfaction of consumers with knowledge (Ong \& Lai, 2007) or knowledge sharing (Ryu et al., 2003).

Many of the instruments have been designed ad-hoc, without an underlying theoretical framework and paying little attention to their psychometric properties (Matzkin, 
2008). Considering those who did it, we observe the one created by (Darroch, 2003), an instrument consisting of 97 items, which later will be reduced to 60 items, grouped into three scales related to the different phases in the KM: the acquisition of knowledge, knowledge dissemination and response knowledge. Regarding the validity of the scale, the predictive one seems demonstrated and the internal obtains a partial support, since the exploratory factor analysis (EFA) seem to support the model but not the confirmatory factor analysis (CFA). All this made us dismiss this instrument to measure the KM.

Additional instruments analyzed were the "Academic Tacit Knowledge Scale". This instrument, developed by Insch, (McIntyre \& Dawley, 2008) is based on a model of $\mathrm{KM}$ that focuses on tacit knowledge, in the context of school or academic performance. It consists of 21 items grouped into six factors: 'Cognitive self-motivation' 'Cognitive selforganization', 'Technical task-individual', 'Technical taskinstitutional', 'Task-related social interaction' and 'General Social interaction'. Both the results of EFA and the CFA support the structure proposed by the authors. However, this questionnaire only pays attention to one kind of knowledge or dimension, the tacit one, neglecting other types, therefore it was also rejected.

The following analyzed instrument is the KMS, developed by (Liu, 2003). It conceives KM as a system, and consists of 54 items grouped into 12 scales that respond to 6 constructs: Use of the KM system; Quality System; Quality of information; Terms of facilitation (attributes and individual perceptions, actual individual learning). According to the author, the instrument has adequate psychometric properties, however the available indicators do not quite fit the proposed model. Therefore the use of this instrument was also dismissed.

Another instrument considered is the "Knowledge Management Assessment Instrument" (KMAI). Developed by Lawson (2004 on Kangas, 2005). This instrument consists of 24 items grouped into six dimensions, and evaluates the KM cycle or process: knowledge creation, knowledge capture, knowledge organization, knowledge storage, knowledge dissemination and application of knowledge. According to the author, this instrument has adequate psychometric properties, however we could not observe such properties, and we consider that the starting model considers different facets of $\mathrm{KM}$, but neglects important elements inside its process.

Seeing no instrument which evaluates properly the basic capabilities that an organization must have for efficient KM ("core capabilities" along the lines of LeonardBarton, 1995), which we consider are those that have a greater relationship with OC of the organization, and pays attention to their psychometric properties, we have seen the necessity of designing and validating an instrument based on the model of knowledge flows by (Leonard-Barton, 1995), which focuses on the different activities of creation and dissemination of knowledge. For this validation, we will turn to university R\&D teams, because we believe that such groups are particularly involved in innovation activities and efficient knowledge management, and have traditionally been neglected in the literature in the pursuit of more business organizations.
According to (Rodriguez, 2013), although R\&D expenditure is a traditional indicator of innovation inputs, it tends to underestimate innovation efforts. As the use of intermediate consumptions from high-innovative industries can contribute to the development of innovations in the client industries, to provide a broader vision of $R \& D$ intensities we must also consider product-embodied Research \& Development.

In this sense, the model of (Leonard-Barton, 1995) focuses on the process of knowledge generation, considering the main variables involved in the acquisition of knowledge until its use. The model includes two distinctive features: the basic organizational capabilities that are related to the knowledge and skills of individuals, physical systems, steering systems and management, and the set of values and norms of the organization; the activities of creation and dissemination of knowledge, which are grouped into four interrelated sets: knowledge acquisition, its application to problem solving, experimentation and implementation and integration.

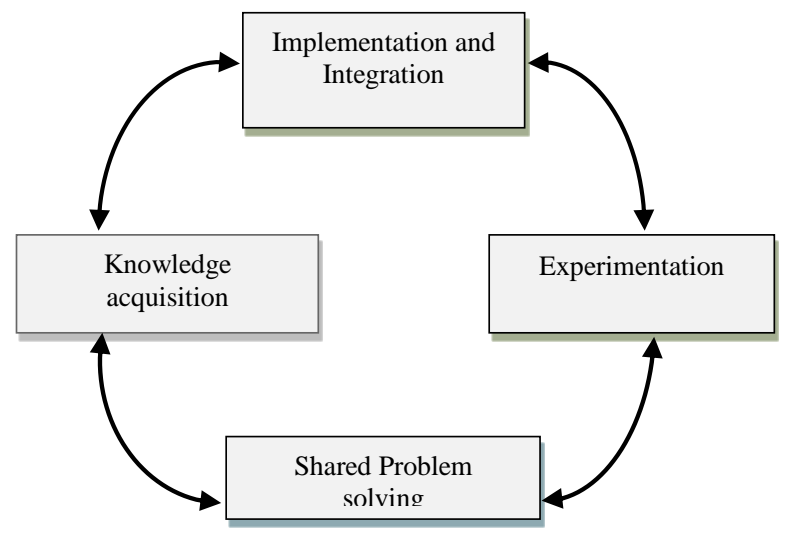

Figure 1. Knowledge Flow Model on R\&D Teams *Adapted From Leonard-Barton's Model (1995)

Both elements of the model are strongly related, as the activities are performed using the capabilities and in turn they renew and generate the others. In our study we try to validate a tool, which evaluates the activities of creation and dissemination of knowledge.

Therefore the objective pursued by this research is threefold; on the one hand, we intend to develop and validate a questionnaire to assess the different tasks or activities of creation and diffusion of knowledge "Knowledge Creation \& Dissemination Survey" (KCD) within the KM; on the other hand, we try to determine how the KM in university $R \& D$ teams is. Given the type of procedure of the research group and the type of tasks to be developed closely linked to innovation and knowledge, we believe that such groups have high levels of KM within them. Finally we analyze the existing relationships between Organizational Culture and Knowledge Management.

Methods of the research: analysis and synthesis, comparison of scientific literature, quantitative data analysis obtained through a questionnaire. The KCD was administered to four different samples from one technical university. Here we will refer to the sample used for the final validation of the scale, 275 participants from $35 \mathrm{R} \& \mathrm{D}$ teams. 


\section{Methodology}

Sample. To validate the KCD four different samples of $\mathrm{R} \& \mathrm{D}$ teams from one technical university were used, as detailed in the procedure section, here we will refer to the sample used for the final validation of the scale, 275 participants from 35 groups. The average participation of members from the 35 groups was $69,36 \%$ (from $22,22 \%$ to $100 \%)$. Most respondents are professors and research staff 154 (56\%), while 46 are PhD Students or Fellows (16,7\%) and 61 support staff (22,2\%). 14 participants did not indicate their status $(5,1 \%)$.

Instrument. Knowledge Creation \& Dissemination Survey $(K C D)$. Questionnaire of 26 items based on the Leonard-Barton's (1995) model of knowledge flows which considers four dimensions that refer to the various phases of the KM: Knowledge acquisition; Implementation and Integration of the Knowledge; Experimentation and Shared Problem solving. Using a Likert response with five response options from strongly disagree (1) to strongly agree (5).

The Spanish version of the Denison Organizational Culture Survey (DOCS), from (Denison \& Neale, 2000; Bonavia et al., 2009). Composed of 60 items, grouped into 12 scales and four second-order factors. With a five-point Likert response $(1=$ strongly disagree to $5=$ Strongly Agree). This instrument has adequate psychometric properties both in its original version $(\alpha=70-92)$ (Denison, $2005,2006)$ and on the Spanish adaptation $(\alpha=0.97$ full scale, dimensions $\alpha=68-93$; Fit index of the Spanish adaptation using ML: $\mathrm{p}<0,001 ; \chi^{2}(\mathrm{df})=174,90(48)$; NNFI $=0,94, \mathrm{CFI}=0,96, \mathrm{GFI}=0,92, \mathrm{SRMR}=0,03)$.

The "Organizational Culture Inventory" (OCI) Cooke and Lafferty (1987) is an instrument designed to evaluate the culture of Organizations in terms of behavioral Norms and expectations related to the shared beliefs and values held by organizational members. It consists of 120 items grouped into 12 culture styles, and three second order factors, that May Influence the thinking and behavior of organizational members, their motivation and performance, and their satisfaction and stress. With a five-point Likert scale $(1=$ strongly disagree to $5=$ Strongly Agree $)$. Cronbach's alpha coefficients support the internal consistency of each of the 12 scales, ranging from 0,65 to 0,95 (Cooke \& Szumal, 1993).

Procedure. On the creation of the KCD international methodological standards recommended by the International Test Commission (ITC) (Muniz \& Hambleton, 2000) were followed:

1) First we perform a focus group with 11 experts on $\mathrm{KM}$, which were leaders of university $\mathrm{R} \& \mathrm{D}$ teams. From the session results and the knowledge of the research group a pull of items was create to collect the different KM activities proposed in Leonard-Barton's (1995) model (Martinez et al., 2005).

2) Later, a preliminary test was created considering those items, which was applied to a sample of 22 subjects, first individually, then by a new focus group. According to the comments of the participants some modifications were done.

3) Then we proceeded to apply the new version of the instrument composed by 24 items, to a new sample of 344 individuals belonging to 30 research groups. Reliability indices were 0,84 for the total scale, while for the dimensions it ranged between 0,60 and 0,79 (Knowledge acquisition $=0,74$; Implementation and Integration $=0,79$; Experimentation $=0,603$, Shared Problem solving $=0,77$ ). Considering the CFA results, the best re-specified model presents the following results: $\mathrm{X} 2(\mathrm{df})=679.71(209,14)$; $\mathrm{X} 2 /(\mathrm{df})=3,25 ; \mathrm{NNFI}=0,74 ; \mathrm{CFI}=0,76 ; \mathrm{GFI}=0,84 ; \mathrm{AGFI}$ $=0,80 ; \mathrm{SRMR}=0,14$. Different CFA for each of the dimensions were calculated separately, which revealed that as it had happened considering reliability; the Experimentation dimension was the most problematic. This led to the reformulation of those items that could be misleading, and also to the addition of two new items to the Experimentation dimension.

4) The questionnaire, which was composed of 26 items, was administered to a new sample of 275 participants from 35 R\&D teams. Afterwards we analyze the psychometric properties of this questionnaire from which the final version of the instrument was made, and it is reported in this work.

Data analysis. The statistical analysis was conducted using the SPSS 21 and EQS 6,1. First, descriptive statistics of every item were calculated followed by the analysis of the reliability and validity of the scale. Thereafter, the correlations between the different dimensions were calculated, then descriptive statistics of KCD on R\&D teams were analysed, and finally the relation between KM and OC dimensions were examined.

\section{Results}

Item analysis. The 26 items of the $\mathrm{KCD}$ scale were analysed. The final items, means, standard deviations, itemtotal correlations and Cronbach's alphas if item is deleted are shown in table 1. Items 9, 18, 19, 21 and 25 are inverted, and they were previously recoded before any calculation.

It seems that in general, all the items contribute to the overall scale. However three items (9, 18 and 25) present a relatively low correlation considering the rest of the scale and, produce a slight improvement in the reliability of the scale when removed.

Reliability analysis. To examine the scale reliability, its internal consistency was calculated using the Cronbach's alpha. However, as this index does not contemplate the influence upon the other construct's reliability, both the composite reliability (CR) and the average variance extracted (AVE) (Fornell \& Larcker, 1981) were calculated. Although the minimum CR value considered being adequate is 0,70 (Nunnally, 1978) and values above 0,50 are recommended for the AVE (Bagozzi \& Yi, 1988; Hair et al., 2006), some articles have considered values above 0,40 for the AVE as adequate (Aldas, 2000). 
Item analysis: Sample Size (n), Mean ( $\bar{x})$, Standard Deviation (sd), Item-Total Correlation (rjx) and Cronbach's Alpha Without the Item (a.-x)

\begin{tabular}{|c|c|c|c|c|}
\hline ITEMS $(\alpha=0,89)$ & $\bar{x}$ & sd & rjx & $\alpha-\mathbf{x}$ \\
\hline \multicolumn{5}{|l|}{ Knowledge acquisition $\alpha=0,82(\mathrm{CR}=0,82 ; \mathrm{AVE}=0,41$ CFA 20 items $)$} \\
\hline $\begin{array}{l}\text { 1. The people of this research group regularly attend conferences and other scientific } \\
\text { meetings. }\end{array}$ & 4,44 & 0,81 & 0,50 & 0,88 \\
\hline 2. In my group much of the time is spent on literature reviews. & 3,49 & 0,96 & 0,39 & 0,88 \\
\hline 3. In general English proficiency in the group is high. & 3,85 & 0,93 & 0,48 & 0,88 \\
\hline 4. In our group we usually participate in multidisciplinary research projects. & 3,75 & 1,05 & 0,53 & 0,88 \\
\hline 5. We frequently visit other centres. & 3,26 & 1,20 & 0,40 & 0,88 \\
\hline 6. In my group we attend training courses regularly. & 3,41 & 1,01 & 0,55 & 0,88 \\
\hline 7. We build relationships with other groups and research institutes. & 3,74 & 0,98 & 0,56 & 0,88 \\
\hline 8. We care about meeting the needs of those who use our knowledge. & 3,67 & 0,94 & 0,57 & 0,88 \\
\hline \multicolumn{5}{|l|}{ Implementation and integration $\alpha=0,76(\mathrm{CR}=0,86 ; \mathrm{AVE}=0,56 \mathrm{CFA} 20$ items $)$} \\
\hline 9. In my group we almost always use the same research methodology. * & 2,56 & 0,95 & $-0,10$ & 0,90 \\
\hline 10. We frequently incorporate new research tools in our work. & 3,65 & 0,89 & 0,63 & 0,88 \\
\hline 11. Our research managers facilitate the adoption of new tools. & 3,85 & 0,84 & 0,68 & 0,88 \\
\hline 12. Our directors promote the use of new tools. & 3,77 & 0,89 & 0,66 & 0,88 \\
\hline $\begin{array}{l}\text { 13. For the introduction of new tools we take into account the opinion of the research } \\
\text { group. }\end{array}$ & 3,75 & 0,88 & 0,61 & 0,88 \\
\hline $\begin{array}{l}\text { 14. In this group we think that the process of adoption of new tools does not } \\
\text { compensate for its results. }\end{array}$ & 3,79 & 0,87 & 0,40 & 0,88 \\
\hline \multicolumn{5}{|l|}{ Experimentation $\alpha=0,68(C R=0,64 ;$ AVE $=0,39$ CFA 20 items $)$} \\
\hline 15. In my group we put originality before the well-established lines of research. & 2,75 & 0,81 & 0,20 & 0,89 \\
\hline 16. We prefer original research on topics at the risk of not contributing anything. & 2,76 & 0,93 & 0,28 & 0,89 \\
\hline $\begin{array}{l}\text { 17. In my group it is well regarded taking risks and exploring unconventional } \\
\text { research topics. }\end{array}$ & 3,35 & 0,91 & 0,57 & 0,88 \\
\hline 18. In my group we usually opt for safe but effective investigations. $*$ & 2,77 & 0,78 & 0,07 & 0,89 \\
\hline 19. In my research group we dismiss risky topics. ${ }^{*}$ & 3,48 & 0,87 & 0,49 & 0,88 \\
\hline 25. In my group errors are penalized. * & 3,95 & 0,92 & 0,21 & 0,89 \\
\hline 26. The leader of our group motivates us to explore new alternatives. & 3,83 & 0,94 & 0,68 & 0,88 \\
\hline \multicolumn{5}{|l|}{ Shared problem solving $\alpha=0,76(\mathrm{CR}=0,82 ;$ AVE $=0,54$ CFA 20 items $)$} \\
\hline 20. We maintain informal discussions among us about work in progress. & 3,87 & 0,96 & 0,51 & 0,88 \\
\hline 21. We tend to solve individually research problems that arise within the group. * & 3,20 & 1,07 & 0,23 & 0,89 \\
\hline $\begin{array}{l}\text { 22. The multidisciplinarity of my group helps us to approach problems from } \\
\text { different perspectives. }\end{array}$ & 3,55 & 1,00 & 0,61 & 0,88 \\
\hline 23. We resort to other peers in those areas we are not specialists in. & 4,24 & 0,80 & 0,56 & 0,88 \\
\hline 24. The collaboration among group members helps performance. & 4,21 & 0,84 & 0,58 & 0,88 \\
\hline
\end{tabular}

Note: * Inverted item; **Acceptable CR $\geq 0.70 * *$ Acceptable AVE $\geq 0.40$

The KCD scale obtained a total alpha value of 0,89 , whilst the different dimensions presented alpha values of between 0,68 and 0,89 (Knowledge acquisition $\alpha=0,82$; Implementation and Integration $\alpha=0,76$; Experimentation $\alpha=0,68$ and Shared Problem solving $\alpha=0,76$ ). Moreover, excepting Experimentation, the four dimensions presented acceptable CR and AVE values (Table 1) (Fornell \& Larcker, 1981; Aldas, 2000; Vila et al., 2000; etc.).

Validity analysis. To analyse the construct validity firstly, two exploratory factorial analysis (EFA) and two confirmatory analyses (CFA) were conducted. Firstly, the adequacy of the sample was evaluated using the KaiserMeyer-Olkin test $(\mathrm{KMO}=0.88)$ and the Barlett's sphericity test $(\mathrm{p}<0.01)$. Here, using the mean component analyses, an EFA was calculated with Varimax rotation, with a selection criteria of eigenvalues higher than 1 . The obtained model consists of 6 factors that almost perfectly replicates the proposed structure and explain $60,68 \%$ of variance. In the second analysis a new EFA with a selection criteria of extracting four factors, trying to replicate the four dimensions proposed in the (Leonard-Barton's, 1995) model, was performed. The four factors seem to explain $52,25 \%$ of the variance, with a structure that seems to replicate that proposed by Leonard-Barton (1995) (F1 (Implementation \& Integration) $=30,26 \%$ model, F2 (Knowledge Acquisition) = 8,96 \%; F3 (Shared Problem solving $=6,11 \% ; \mathrm{F} 4($ Experimentation $)=6,92 \%)$. Some of the items $(4,8,9,22$ and 26) could be deleted as they saturate in more than one dimension.

Continuing the validation process a CFA with ML (Maximum likelihood) estimation, considering the 26 items grouped into the four activities of knowledge management proposed by Leonard-(Barton, 1995). However this model did not provide an adequate fit, so it was necessary to perform a re-specification, the resulting questionnaire consists of 20 items grouped into four dimensions according to the following structure: Knowledge Acquisition: Items 1, 2, 3 6, 7 and 8; Implementation and Integration: items from 10 to 14; Experimentation: items 17, 19 and 25; Shared Problem solving: 20, 22, 23 and 24. In this section we present only the information about this re-specified model. 
As regards the significance of the $\chi^{2}(<0,01)$, in no case an adequate fit can be ensured. Nevertheless, as this statistic is closely related to the sample size, other indicators were analyzed, such as the ratio between $\chi^{2}(324,03)$ and its degrees of freedom $(146)\left(\chi^{2} / \mathrm{df}=2,22\right.$; values below five considered acceptable) goodness of fit indexes like the NonNormed Fit Index (NNFI $=0,90)$, the Comparative Fit Index $(\mathrm{CFI}=0,92)$ and the Incremental Fit Index $(\mathrm{IFI}=0,92)$ (values over 0.90 indicate an adequate fit) (MacCallum \& Austin, 2000); and the Standardized Root Mean-Square Residual $(\mathrm{SRMR}=0,04)$, where values under 0,05 are indicators of an adequate fit (Browne \& Cudeck, 1993). Considering the results, in general the model seems to present an adequate fit.

In order to increase the empirical evidence over the construct validity, the convergent and discriminant validity of the scale was calculated. The convergent validity appeared to be adequate, showing a significant, strong correlation between the items of the scale and the latent variables that they were supposed to measure, with $t$ values over 3,291 in every case (Vila et al., 2000) and loads for every factor of over 0,70 on average (Hair et al., 2006), which did not improve when new loads were included.
On the other hand, the discriminant validity was evaluated by means of the average extracted variance test (AEV) (Fornell \& Larcker, 1981). To determine the existence of the discriminant validity, the EAV square root must be higher than the correlation among the pairs of factors or dimensions considered (Fornell \& Larcker, 1981; Vila et al., 2000). The results, displayed in table 2, suggest acceptable discriminant validity.

The content validity was analyzed considering 11 experts. They judged the items to be suitable considering the constructs that were intended to measure (Martinez et al., 2005).

Following the analysis and as it is suggested by the literature, the relations of the construct with other constructs were examined. To this end a model using ML, on which the 12 dimensions of the DOCS grouped into their foursecond order factors were predictors of the four dimensions of the KCD. The results $\left(\mathrm{p}<0,001 ; \chi^{2}(\mathrm{df})=240,39(86)\right.$; $\mathrm{NNFI}=0,93, \mathrm{CFI}=0,95, \mathrm{GFI}=0,95, \mathrm{SRMR}=0,04)$ seems to contribute to the construct validity.

Correlations. The next step in the validation of the scale was the analysis of the Pearson correlations between the instrument dimensions (Table 2).

Table 2

Pearson Correlations for KCD Dimensions and AVE Value

\begin{tabular}{lllll}
\hline & $\mathbf{1}$ & $\mathbf{2}$ & $\mathbf{3}$ \\
\hline Knowledge acquisition & 0,64 & & \\
Implementation and Integration & 0,47 & 0,75 & \\
Experimentation & 0,41 & 0,39 & 0,62 \\
Shared Problem solving & 0,48 & 0,46 & 0,41 \\
\hline
\end{tabular}

$*$ All correlations are significant $(p<0,01) . * * A V E$ Square root in the diagonal.

There were statistically significant moderately high and positive correlations among every dimension $(\mathrm{p}<0,01)$.
Description of KCD on R\&D teams. The next aspect analyzed refers to the KM in university R\&D teams. Table 3 presents main Statistical descriptive of KCD dimensions.

Statistical Descriptive of the 35 Groups on KCD Dimensions

Table 3

\begin{tabular}{|c|c|c|c|c|}
\hline & Knowledge acquisition & $\begin{array}{c}\text { Implementation and } \\
\text { Integration }\end{array}$ & Experimentation & $\begin{array}{c}\text { Shared Problem } \\
\text { solving }\end{array}$ \\
\hline Mean & 3,79 & 3,79 & 3,59 & 4,08 \\
\hline Mode & 3,50 & 3,80 & 3,33 & 4,00 \\
\hline $\mathrm{Sd}$ & 0,51 & 0,59 & 0,61 & 0,53 \\
\hline Minimum & 1,67 & 1,40 & 1,00 & 1,00 \\
\hline Maximum & 5,00 & 5,00 & 5,00 & 5,00 \\
\hline
\end{tabular}

Then, considering the mean \pm a standard deviation low, medium and high levels were determined (Table 4).

Table 4

Classification of 35 Groups on KCD Dimensions

\begin{tabular}{|c|c|c|c|}
\hline & Category & Frequency & $\% 65$ groups \\
\hline \multirow{3}{*}{ Knowledge acquisition } & LL & 5 & 14,7 \\
\hline & ML & 26 & 76,5 \\
\hline & HL & 3 & 8,8 \\
\hline \multirow{3}{*}{$\begin{array}{l}\text { Implementation and } \\
\text { Integration }\end{array}$} & LL & 8 & 22,9 \\
\hline & ML & 21 & 60,0 \\
\hline & HL & 6 & 17,1 \\
\hline \multirow{3}{*}{ Experimentation } & $\mathrm{LL}$ & 5 & 16,7 \\
\hline & ML & 23 & 76,7 \\
\hline & HL & 2 & 6,7 \\
\hline \multirow{3}{*}{ Shared Problem solving } & $\mathrm{LL}$ & 7 & 20,0 \\
\hline & ML & 21 & 60,0 \\
\hline & $\mathrm{HL}$ & 7 & 20,0 \\
\hline
\end{tabular}

*Groups in which at least the $65 \%$ of participants have responded. **LL-low level; ML-medium level; HL-high level. 
Considering the results, it seems that $R \& D$ teams present medium-high rates in all the dimensions, with the highest results on Shared Problem solving and the lowest on Experimentation.

Relations between Knowledge Management and Organizational Culture. The last of the objectives pursued on the research refers to test the empirical relationship between KM and OC. First, Pearson correlations between the second-order factors of the "OCI" and "DOCS" (OC measures) and the four dimensions of KCD (KM measures) were calculated (Table 5).

Pearson Correlations of $\mathrm{OC}$ and $\mathrm{KM}$

Table 5

\begin{tabular}{|c|c|c|c|c|c|}
\hline & & Knowledge acquisition & $\begin{array}{c}\text { Implementation and } \\
\text { Integration }\end{array}$ & Experimentation & $\begin{array}{c}\text { Shared Problem } \\
\text { solving }\end{array}$ \\
\hline \multirow{3}{*}{ OCI } & Constructive & 0,41 & 0,43 & 0,50 & 0,50 \\
\hline & Passive-Defensive & $-0,29$ & $-0,25$ & $-0,33$ & $-0,27$ \\
\hline & Aggressive-Defensive & $-0,20$ & $-0,22$ & $-0,26$ & $-0,25$ \\
\hline \multirow{4}{*}{ DOCS } & Involvement & 0,57 & 0,54 & 0,53 & 0,61 \\
\hline & Consistency & 0,54 & 0,50 & 0,45 & 0,55 \\
\hline & Adaptability & 0,57 & 0,56 & 0,51 & 0,52 \\
\hline & Mission & 0,56 & 0,47 & 0,41 & 0,48 \\
\hline
\end{tabular}

*All correlations are significant $(\mathrm{p}<0,01)$

Significant correlations $(\mathrm{p}<0,01)$ were observed between all dimensions of OC and KM, with higher values considering the DOCS than the OCI. The Passive-defensive and the Aggressive-defensive cultures present lower and negative correlations with KCD dimensions, while Constructive Culture presents highest and positive correlations.

Next, different structural equation models were performed to determine the relationship between $\mathrm{OC}$ and KM. The model that presents the best fit considers that KCD dimensions are caused by the second-order factors of the DOCS and OCI (Figure 2).

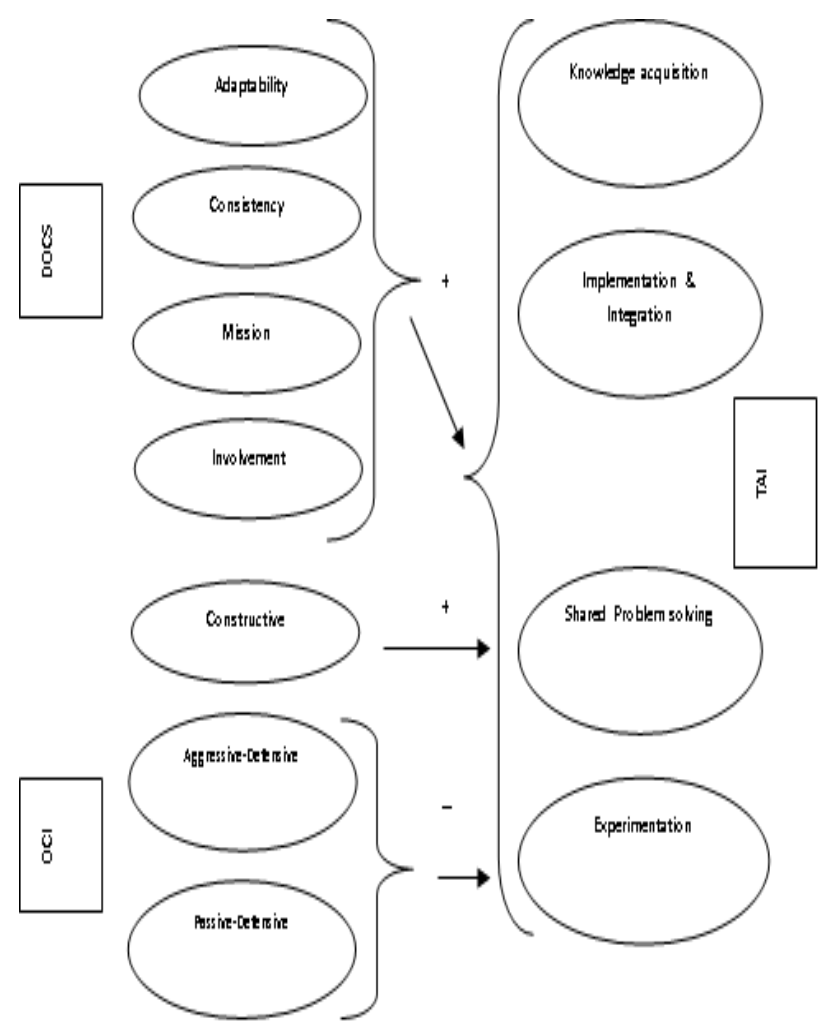

Figure 2. Path Model: Relations between OCI, DOCS and $\mathrm{KCD}$

$$
\begin{gathered}
* \chi^{2} / \mathrm{df}=24,297(6)(\mathrm{p}<0,001) ; \mathrm{NFI}=0,93 ; \mathrm{CFI}=0,94 ; \mathrm{IFI} \\
=0,95 ; \mathrm{RMSEA}=0,04 ; \alpha=0,77
\end{gathered}
$$

\section{Conclusions and Discussion}

The KM is today a discipline that has experienced considerable growth on both theoretical and empirical level (Chua \& Heng, 2010), however, and as with many other constructs from psychology or other related sciences, there is a gap on the literature considering the measurement of KM (Chen \& Chen, 2006), especially with regard to selfadministered instrument that are not focused on a particular aspect of the process of $\mathrm{KM}$ or a particular type of knowledge, but consider the phenomena from a holistic perspective.

From this point of view, the research that has been conducted here, has focalized on the creation and subsequent validation of a useful instrument to assess KM practices. To do this we focalize on the Leonard-Barton's knowledge flow model (1995) to create the Knowledge Creation \& Dissemination Survey (KCD). Essentially, the results of the KCD have been satisfactory, supporting the questionnaire validity. The descriptive analysis of the items shows an adequate contribution to the overall scale and a relatively high correlation with the full scale, although three of them should be eliminated or reformulated, these are items 9, 18 and 25 (which was also suggested considering other tests).

Afterwards, the validity of the scale was studied leading to a model with four factors or dimensions that explain $52,25 \%$ of the variance, show high correlations with each other and seem to accurately reproduce the structure proposed by (Leonard-Barton, 1995). In general, the convergent and the discriminant validity are satisfactory. The link between DOCS and KCD was also proved, which also contributes to the construct validity.

Considering the different dimensions contained in the instrument, all seem to present enough empirical support regarding its reliability and validity, although the Experimentation dimension is the most problematic in all tests, subsequent studies should try to develop and test new items with the goal of strengthening this dimension.

Considering the levels on the different instruments, on $\mathrm{R} \& \mathrm{D}$ teams $\mathrm{KM}$ is high, the prevailing culture is 
constructive, where communication, cooperation and support, prevails, all these are dimensions that promote an adequate climate to KM (Hult, 1998; Hult et al., 2000; Janz \& Prasarnphanich, 2003; Al-Alawi et al., 2007; etc.).

Finally the link between KM and OC seem to be proved (McManus \& Loughridge, 2002; Thoben et al., 2002; Mason \& Pauleen, 2003; Hong et al., 2011; etc.), specifically, it seem that the OC influences greater on the KM than the latter on the OC (Leonard-Barton, 1995; Janz \& Prasarnphanich, 2003). All these results have a special interest if we consider that in the scientific literature such relationship has been proposed from a theoretical or conceptual approach, but not test from the empirical level.

As previously noted, scientific literature has pointed out the importance of $\mathrm{KM}$ to improve the efficiency and effectiveness of organizations (Barney, 1991; LeonardBarton, 1995; Grant, 1996; Berman et al., 2002; Choi \& Lee, 2003; Chua \& Heng, 2010; Chang \& Chuang, 2011; etc.), or to improve satisfaction and well-being of workers (Nonaka \& Takeuchi, 1995; Carnerio, 2000; Yang \& Wan, 2004; Massa \& Testa, 2009; Mohamed et al., 2009; Cantnera et al., 2011; etc.) to mention just few examples. Thus, research into KM is important in order to gain greater insight into group or organization performance. Hence, the
KCD survey possesses enough empirical support to be considered a valid, useful instrument for the evaluation of KM activities, showing information about the group performance on the $\mathrm{KM}$ activities and offering the possibility of planning an intervention.

Although the process of validation of the instrument must continue, extending the sample both in terms of its size and also on its diversity, the results presented here, seem to justify adequate reliability and validity, for an instrument of 20 items grouped into the four-dimensional model of (Leonard-Barton, 1995). The evidence provided justifies the diagnostic utility of the tool with Spanish samples. However, it would be interesting to deepen the study by linking KM with other variables suggested in the literature as the performance (Leonard-Barton, 1992; Prusak, 1996; Teece, 1998; Berman et al., 2002; Choi \& Lee, 2003; Chua \& Heng, 2010; Chang \& Chuang 2011; etc.).

Finally, considering the problems with the measures in the KM context, the few existing questionnaires and the relatively little concern about the psychometric properties of them, and their samples it is necessary to highlight the importance of this research. Therefore, the KCD questionnaire can be considered as a useful, practical tool to evaluate group practices on KM.

\section{References}

Al-Alawi, A. I., Al-Marzooqi, N. Y., \& Mohammed, Y. F. (2007). Organizational culture and knowledge sharing: critical success factors. Journal of Knowledge Management, 11(2), 22-42. http://dx.doi.org/10.1108/13673270710738898

Aldas, J. (2007). Analisis factorial confirmatorio. Apuntes y ejercicios. Material de la asignatura de nalisis de datos avanzado del doctorado en Marketing [Confirmatory factor analysis. Notes and exercises. Notes of the subject of advanced data analysis of the doctorate in Marketing]. Departamento de comercializacion e investigacion de mercados. Universidad de Valencia.

Alves, J. B. (2014). Knowledge management in a changing society. International Review of Management and Business Research, 3(3), 1401-1407.

An, X., Deng, H., Chao, L., \& Bai, W. (2014). Knowledge management in supporting collaborative innovation community capacity building. Journal of Knowledge Management, 18(3), 574-590. http://dx.doi.org/10.1108/JKM-10-2013-0413

Bagozzi, R.P., \& Yi, Y. (1988). On the evaluation of structural equation models. Journal of the Academy of Marketing Science, 16(1), 74-94. http://dx.doi.org/10.1007/BF02723327

Barney, J. B. (1991). Firm resources and sustained competitive advantage. Journal of Management, 17(1), 99-120. http://dx.doi.org/10.1177/014920639101700108

Berman, S. L., Down, J., \& Hill, C. W. L. (2002). Tacit knowledge as a source of competitive advantage in the National Basketball Association. Academy of Management Journal, 45(1), 13-31. http://dx.doi.org/10.2307/3069282

Birasnav, M. (2014). Knowledge management and organizational performance in the service industry: The role of transformational leadership beyond the effects of transactional leadership. Journal of Business Research, 67(8), 16221629. http://dx.doi.org/10.1016/j.jbusres.2013.09.006

Bonavia, T., Prado, V., \& Barbera, D. (2009). Adaptacion al castellano y estructura factorial del Denison organizational culture survey [Spanish adaptation and factor structure of the Denison organizational culture survey]. Psicothema, 21(4), 633-638.

Bowen, T. S. (1999). Making knowledge mean business: Vendors rush to jump on bandwagon. InfoWorld, 21(2), 69-79.

Browne, M. W., \& Cudeck, R. (1993). Alternative ways of assessing model fit. In: Bollen, K.A. \& Long, J.S. (Eds.) Testing structural equation models. Beverly Hills, CA: Sage

Camison, C., \& Fores, B. (2010). Knowledge absorptive capacity: New insights for its conceptualization and measurement. Journal of Business Research, 63(7), 707-715. http://dx.doi.org/10.1016/j.jbusres.2009.04.022

Cantner, U., Joel, K., \& Schmidt, T. (2011). The effects of knowledge management on innovative success - An empirical analysis of German firms. Research Policy, 40(10), 1453-1462. http://dx.doi.org/10.1016/j.respol.2011.06.007

Carneiro, A. (2000). How does knowledge management influence innovation and competitiveness? Journal of Knowledge Management, 4(2), 87-98. http://dx.doi.org/10.1108/13673270010372242 
Chang, J., Choi, B., \& Lee, H. (2004). An organizational memory for facilitating knowledge: an application to e-business architecture. Expert Systems with Applications, 26(2), 203-215. http://dx.doi.org/10.1016/S0957-4174(03)00135-0

Chang, T. C., \& Chuang, S. H. (2011). Performance implications of knowledge management processes: Examining the roles of infrastructure capability and business strategy. Expert Systems with Applications, 38(5), 6170-6178. http://dx.doi.org/10.1016/j.eswa.2010.11.053

Chen, C., \& Huang, J.-W. (2007). How organizational climate and structure affect knowledge management-The social interaction perspective. International Journal of Information Management, 27(2), 104-118. http://dx.doi.org/10. 1016/j.ijinfomgt.2006.11.001

Chen, M., \& Chen, A. (2006). Knowledge management performance evaluation: A decade review from 1995 to 2004. Journal of Information Science, 32(1), 17-38. http://dx.doi.org/10.1177/0165551506059220

Choi, B., \& Lee, H. (2003). An empirical investigation on KM styles and their effect on corporate performance. Information and Management, 40(5), 403-417. http://dx.doi.org/10.1016/S0378-7206(02)00060-5

Chua, A., \& Heng, S. K. (2010). A knowledge management perspective on art education. International Journal of Information Management, 30(4), 326--334. http://dx.doi.org/10.1016/j.ijinfomgt.2009.12.002

Cooke, R., \& Lafferty, J. (1987). Organizational culture inventory (OCI). Plymouth, MI: Human Synergistics.

Cooke, R., \& Szumal, J. L. (1993). Measuring normative beliefs y shared behavioural expectations in organizations: The reliability $\mathrm{y}$ validity of the organizational culture inventory. Psychological Reports, 72, $1299-1330$. http://dx.doi.org/10.2466/pr0.1993.72.3c.1299

Darroch, J. (2003). Developing a measure of knowledge management behaviors and practices. Journal of Knowledge Management, 7(5), 41-54. http://dx.doi.org/10.1108/13673270310505377

Denison, D., \& Neale, W. (2000). Denison organizational culture survey. Ann Arbor: Denison Consulting.

Drucker, P. (1993). Post capitalist society. New York: HarperCollins.

Fenwick, M. (2005). Extending strategic human resource management research and pedagogy to the non-profit multinational. International Journal of Human Resource Management, 16(4), 497-512. http://dx.doi.org/10. 1080/09585190500051480

Fornell, C., \& Larcker, D. F. (1981). Evaluating structural equations models with unobservable variables and measurement error. Journal of Marketing Research, 18(1), 39-50.

Gibbert, M., Leibold, M., \& Probst, G. (2002). Five styles of customer knowledge management, and how smart companies use them to create value. European Management Journal, 20(5), 459-469. http://dx.doi.org/10.1016/S02632373(02)00101-9

Gold, A. H., Malhotra, A., \& Segars, A. H. (2001). Knowledge management: an organizational capabilities perspective. Journal of Management Information Systems, 18(1), 185-214.

Grant, R. M. (1996). Toward a knowledge-based theory of the firm. Strategy Management Journal, 17(S2), 109-122. http://dx.doi.org/10.1002/smj.4250171110

Hair, J. F., Black, W. C., Babin, B. J., Anderson, R. E., \& Tatham, R. L. (2006). Multivariate data analysis (6 ed.). New Jersey: Pearson.

Halawi, L. A., McCarthy, R., \& Aronson, J. (2008). An empirical investigation of knowledge management systems' success. Journal of Computer Information Systems, 48(2), 121-143.

Harrington, S., \& Guimaraes, T. (2005). Corporate culture, absorptive capacity and IT success. Information and Organization, 15(1), 39-63. http://dx.doi.org/10.1016/j.infoandorg.2004.10.002

Hong, D., Suh, E., \& Koo, C. (2011). Developing strategies for overcoming barriers to knowledge sharing based on conversational knowledge management: A case study of a financial company. Expert Systems with Applications, 38(12), 14417-14427. http://dx.doi.org/10.1016/j.eswa.2011.04.072

Hult, G. T. M. (1998). Managing the international strategies sourcing process as a market-driven organizational learning system. Decision Sciences, 29(1), 193-216. http://dx.doi.org/10.1111/j.1540-5915.1998.tb01349.x

Hult, G. T. M., Hurley, R. F., Giunipero, L. C., \& Nichols, E. L., Jr. (2000). Organizational learning in global purchasing: A model and test of internal users and corporate buyers. Decision Sciences, 31(2), 293-325. http://dx.doi.org/10. 1111/j.1540-5915.2000.tb01625.x

Insch, G., Mcintyre, N., \& Dawley, D. (2008). Tacit knowledge: a refinement and empirical test of the academic Tacit knowledge scale. The Journal of Psychology, 142(6), 561-579. http://dx.doi.org/10.3200/JRLP.142.6.561-580

Janz, B. D., \& Prasarnphanich, P. (2003). Understanding the antecedents of effective knowledge management: The importance of a knowledge-centered culture. Decision Sciences, 34(2), 351-384. http://dx.doi.org/10.1111/15405915.02328 
Vicente J. Prado-Gasco, Ismael Quintanilla Pardo, Ferran Calabuig-Moreno, Jolita Vveinhardt Knowledge Management...

King, A. W., \& Zeithaml, C. P. (2001). Competencies and firm performance: Examining the causal ambiguity paradox. Strategic Management Journal, 22(1), 75-99. http://dx.doi.org/10.1002/1097-0266(200101)22:1<75::AIDSMJ145>3.0.CO;2-I

King, A. W., \& Zeithaml, C. P. (2003). Measuring organizational knowledge: a conceptual and methodological framework. Strategic Management Journal, 24(8), 763-772. http://dx.doi.org/10.1002/smj.333

Leonard-Barton, D. (1995). Wellsprings of knowledge: Building and sustaining the sources of innovation. Harvard Business Scholl Press.

Lettieri, E., Borga, F., \& Savoldelli, A. (2004). Knowledge management in non-profit organizations. Journal of Knowledge Management, 8(6), 16-30. http://dx.doi.org/10.1108/13673270410567602

Liu, S. C (2003). A Study of Factors that Facilitate Use of Knowledge Management Systems and the Impact of Use on Individual Learning. Thesis Dissertation, Claremont Garduate University. Claremont. California

MacCallum, R. C., \& Austin, J. T. (2000). Applications of structural equation modeling in psychological research. Annual Review of Psychology, 51, 201-226.

Martinez, J. L., De los Reyes, E., Quintanilla, I., \& Bonavia, T. (2005). Barriers and facilitators to the generating activities of knowledge in R\&D teams: a qualitative approach. Book of Abstracts, July 2005, 9th European Congress of Psychology.

Martin-Rojas, R., Garcia-Morales, V. J., \& Mihi-Ramirez, A. (2014). Knowledge-based organization in tourism industry. Inzinerine Ekonomika-Engineering Economics, 25(1), 82-93. http://dx.doi.org/10.5755/j01.ee.25.1.2030

Mason, D., \& Pauleen, D. (2003). Perceptions of knowledge management: a qualitative analysis. Journal of Knowledge Management, 7(4), 38-48. http://dx.doi.org/10.1108/13673270310492930

Massa, S., \& Testa, S. (2009). A knowledge management approach to organizational competitive advantage, evidence from the food sector. European Management Journal, 27(2), 129-141. http://dx.doi.org/10.1016/j.emj.2008.06.005

Matzkin, D. S. (2008). Knowledge management in the Peruvian non-profit sector. Journal of Knowledge Management, 12(4), 147-159. http://dx.doi.org/10.1108/13673270810884318

McManus, D., \& Loughridge, B. (2002). Corporate information, institutional culture and knowledge management: A Uk university library perspective. New Library World, 103(9), 320-327. http://dx.doi.org/10.1108/03074800210445453

Melnikas, B. (2011). Knowledge economy: synergy effects, interinstitutional interaction and internationalization processes. Inzinerine Ekonomika-Engineering Economics, 22(4), 367-379. http://dx.doi.org/10.5755/j01.ee.22.4.712

Mohamed, M., Stankosky, M., \& Mohamed, M. (2009). An empirical assessment of knowledge management criticality for sustainable development. Journal of Knowledge Management, 13(5), 271-286. http://dx.doi.org/10.1108/136732709 10988105

Muniz, J., \& Hambleton, R. K. (2000). Adaptacion de los tests de unas culturas a otras [Adapting tests across cultures]. Metodologia de las Ciencias del Comportamiento, 2(2), 129-149.

Nonaka, I., \& Takeuchi, N. (1995). The knowledge creating company. Oxford University Press.

Nunnally, J. C. (1978). Psychometric theory. New York: McGraw-Hill.

Ong, C. S., \& Lai, J. Y. (2007). Measuring user satisfaction with knowledge management systems: scale development, purification, and initial test. Computers in Human Behavior, 23(3), 1329-1346. http://dx.doi.org/10.1016/j. chb.2004.12.012

Pan, S. L., \& Scarbrough, H. (1998). A socio-technical view of knowledgesharing at Buckman laboratories. Journal of Knowledge Management, 2(1), 55-66. http://dx.doi.org/10.1108/EUM0000000004607

Ponte, C. D., \& Johnson-Tribino J. (2005). Attitudes and knowledge about pain: an assessment of West Virginia family practitioners. Family Medicine, 37(7), 477-480.

Prusak, L. (1996). The knowledge advantage. Strategy and Leadership, 24(2), 6-8.

Quinn, J. (1992). Intelligent enterprise: A knowledge y service basic paradigm for industry. New York: The Free Press.

Ramirez, A. M., \& Girdauskiene, L. (2013a). The relationship between knowledge and green logistics. A theoretical approach. Inzinerine Ekonomika-Engineering Economics, 24(3), 267-274. http://dx.doi.org/10.5755/j01.ee.24.3.3312

Ramirez, A. M., \& Girdauskiene, L. (2013b). Creation of knowledge and reverse logistics. empirical analysis from perspective of the resource based view theory. Inzinerine Ekonomika-Engineering Economics, 24(5), 478-487. http://dx.doi.org/10.5755/j01.ee.24.5.2689

Ramirez, A. M., \& Morales, V. J. G. (2011). Improving competitiveness trough creation of knowledge and reverse logistics. Inzinerine Ekonomika-Engineering Economics, 22(4), 443-450. http://dx.doi.org/10.5755/j01.ee.22.4.719

Ramirez, A. M., Morales, V. J. G., \& Rojas, R. M. (2011). Knowledge creation, organizational learning and their effects on organizational performance. Inzinerine Ekonomika-Engineering Economics, 22(3), 309-318. http://dx.doi.org/ 10.5755/j01.ee.22.3.521 
Rodriguez, M. (2013). Knowledge-intensive business services and R\&D diffusion: A comparative assessment of some eu27 countries. Inzinerine Ekonomika-Engineering Economics, 24(4), 300-308. http://dx.doi.org/10.5755/j01. ee.24.4.2081

Rodriguez, M. (2014). Innovation, Knowledge Spillovers and High-Tech Services in European Regions. Inzinerine Ekonomika-Engineering Economics, 25(1), 31-39. http://dx.doi.org/10.5755/j01.ee.25.1.3207

Ryu, S., Ho, S., \& Han, I. (2003). Knowledge sharing behavior of physicians in hospitals. Expert Systems with Applications, 25(1), 113-122. http://dx.doi.org/10.1016/S0957-4174(03)00011-3

Sanchez, P., Chaminade, C., \& Escobar, C. (1999). En busca de una teoria sobre la medicion y gestion de los intangibles en la empresa: una aproximacion metodologica [Seeking a theory on the measurement and management of intangibles in the enterprise: a methodological approach]. Ekonomiaz. Revista Vasca de Economia, 45, 188-213.

Sedziuviene, N., \& Vveinhardt, J. (2009). The paradigm of knowledge management in higher educational institutions. Inzinerine Ekonomika-Engineering Economics, 5, 79-90.

Sedziuviene, N., \& Vveinhardt, J. (2010). Competitiveness and innovations: role of knowledge management at a knowledge organization. Inzinerine Ekonomika-Engineering Economics, 21(5), 525-536.

Singh, M., Shankar, R., Narain, R., \& Kumar, A. (2006). Survey of knowledge management practices in Indian manufacturing industries. Journal of Knowledge Management, 10(6), 110-128. http://dx.doi.org/10.1108/136732 70610709251

Spender, J. C., \& Grant, R. M. (1996). Knowledge and the firm: overview. Strategic Management Journal, 17(S2), 5-9. http://dx.doi.org/10.1002/smj.4250171103

Srisamran, P., \& Ractham, V. V. (2014). Customer-centric knowledge creation for customer relationship management. Journal of Applied Business Research, 30(2), 397-408.

Steyn, N., Labadarios, D., Nel, J., \& Heidi-Lee, R. (2005). Development and validation of a questionnaire to test knowledge and practices of dietitians regarding dietary supplements. Nutrition, 21(1), 51-58. http://dx.doi.org/10.101 6/j.nut.2004.09.008

Teece, D. J. (1998). Capturing value from knowledge assets: the new economy, markets for know-how and intangible assets. California Management Review, 40(3), 55-79.

Thoben, K. D., Weber, F., \& Wunram, M. (2002). Barriers in knowledge management and pragmatic approaches. Studies in Informatics and Control, 11(1), 7-15.

Thoene, M. A., \& Buszko, A. (2014). Quantitative model of tacit knowledge estimation for pharmaceutical industry. Inzinerine Ekonomika-Engineering Economics, 25(1), 40-46. http://dx.doi.org/10.5755/j01.ee.25.1.5083

Vila, N., Kuster, I., \& Aldas, J. (2000). Desarrollo y validacion de escalas de medida en Marketing [Development and validation of measurement scales in Marketing]. Working Paper. Facultat d'Economia. Universitat de Valencia, 104, $1-73$.

Yang, J. (2010). The knowledge management strategy and its effect on firm performance: A contingency analysis. International Journal of Production Economics, 125, 215-223. http://dx.doi.org/10.1016/j.ijpe.2010.03.012

Yang, J. T., \& Wan, C. S. (2004). Advancing organizational effectiveness and knowledge management implementation. Tourism Management, 25(5), 593-601. http://dx.doi.org/10.1016/j.tourman.2003.08.002

Zhuge, H. (2002). A knowledge flow model for peer-to-peer team knowledge sharing and management. Expert System with Applications, 23(1), 23-30. http://dx.doi.org/10.1016/S0957-4174(02)00024-6

Zieba, M., \& Zieba, K. (2014). Knowledge management critical success factors and the innovativeness of KIBS companies. Inzinerine Ekonomika-Engineering Economics, 25(4), 458-465. http://dx.doi.org/10.5755/j01. ee.25.4.6494

The article has been reviewed.

Received in February, 2015; accepted in September, 2015. 